\title{
EFFECT OF SAMPLING TIME ON FUZZY LOGIC CONTROL OF DC MOTOR DRIVES
}

\author{
R. MOSTAFA \\ Egyption Armed Forces
}

\begin{abstract}
This paper describes the effect of sampling time on the speed control of a separately excited dc motor which uses phase controlled bridge converter and fuzzy logic control. In order to accomplish a satisfactory damping characteristics over a wide range of operation the speed deviation $(\Delta \omega)$ and the acceleration $\left(\Delta \omega^{\circ}\right)$ were taken as input signals to the fuzzy controller. These variables have significant effects on the damping of shaft mechanical oscillations. The method used for defuzzification is the commonly used centroid method. By changing the sampling time over a wide range the results obtained by fuzzy logic controller are compared with those obtained by using conventional controllers.
\end{abstract}

\section{INTRODUC.TION}

During the past years, many control techniques have been developed for improving the performance of motor drives. The most widely used control method is perhaps the Proportional-Integral-Derivative (PID). The limitations of fixed parameters PID control have lead to advanced control schemes, such as, self tuning control, sliding mode control and fuzzy logic control [1]. Although, all these types of control controller are capable of offering better dynamic performance than a fixed parameters [2], the fuzzy logic control appears to be the most promising, due to its lower computational burden and robustness. Also in the design of fuzzy logic control techniques, unlike most conventional methods, a mathematical model is not required to describe the system under study.

\section{MOTOR MODEL}

The speed control scheme of a dc motor fed from a three phase full-wave bridge controlled rectifier at constant excitation voltage is shown in Fig.(1). The dynamic model of the motor is described by a set of electrical and mechanical differential equations [3] in continuous current domain as follows: 


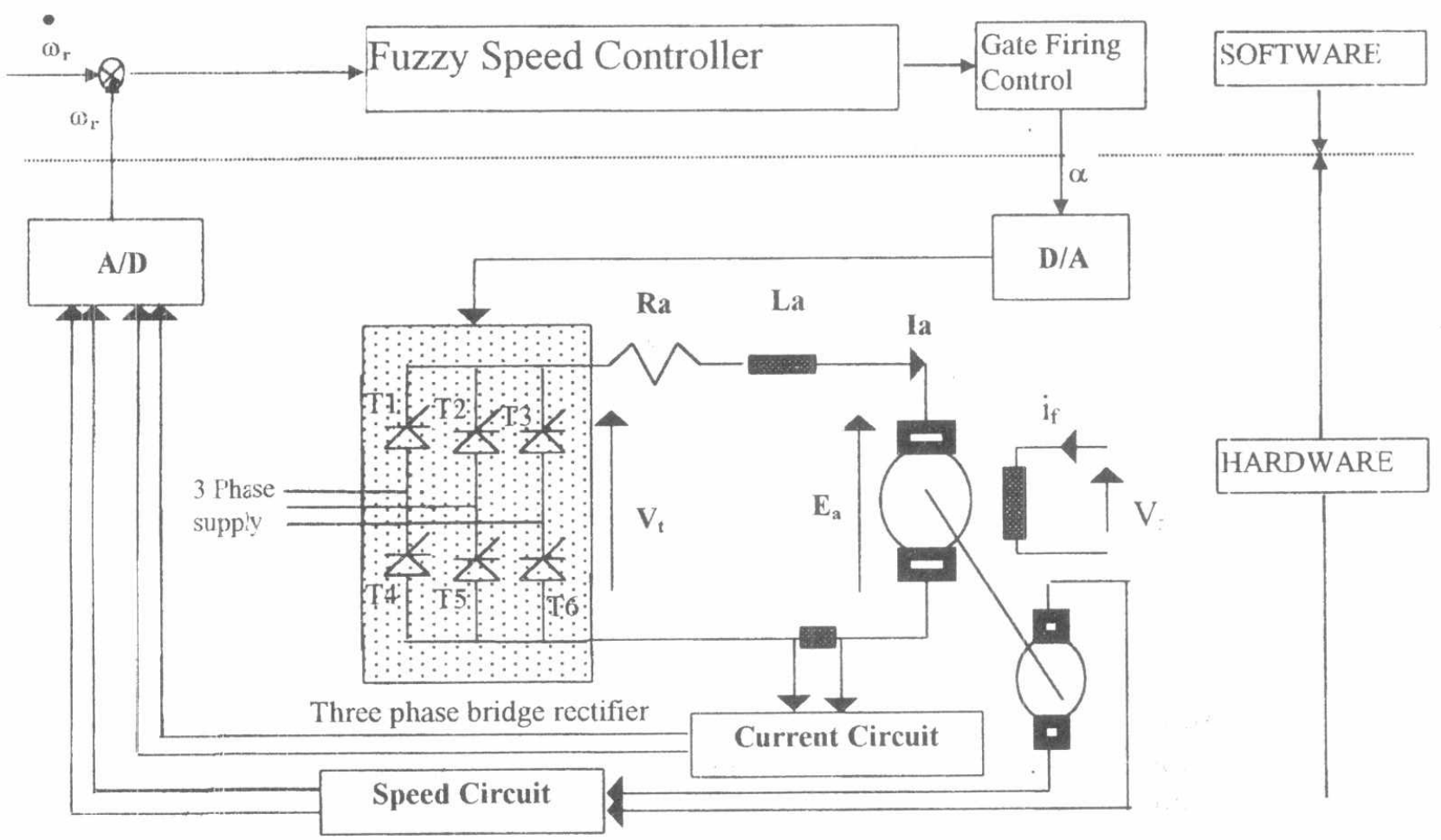

Fig. (11) The proposed speed control structure

\section{Armature equation}

$V(\omega t)=E_{a}+i_{a}(\omega t) \times R_{a}+L_{a}(\omega t) \times d i_{a} / d t$

where, $E_{a}=k_{m} \times \omega_{r}$

$\omega_{\mathrm{r}}:$ The rotor speed in Rad./Sec.

$\mathrm{k}_{\mathrm{m}}$ : The back e.m.f. constant in Volt.Sec./Rad.

\section{The Shaft Mechanical Equation}

$\mathrm{T}_{\text {elec. }}=\mathrm{T}_{\text {load }}+\mathrm{B} \times \omega_{\mathrm{r}}+\mathrm{J} \times \mathrm{d} \omega_{\mathrm{r}} / \mathrm{dt}$

$\mathrm{T}_{\text {elec. }}=\mathrm{k}_{\mathrm{t}} \times \mathrm{i}_{\mathrm{a}}(\omega \mathrm{t}) \quad$ and $\quad \mathrm{T}_{\text {load }}=\mathrm{k}_{0} \times \omega_{\mathrm{r}}^{2}-\mathrm{T}_{\mathrm{d}}$

where:

$\mathrm{T}_{\text {load }} \quad$ : The load torque which is considered as a function of $\omega_{\mathrm{r}}{ }^{2}$ such as for fan or pump type load.

$\mathrm{T}_{\mathrm{d}} \quad$ : The disturbance torque $(5 \div 50 \%)$ of the full load torque

$\mathrm{k}_{\mathrm{t}} \quad$ : The torque constant in V.Sec./Rad. and equals to $\mathrm{k}_{\mathrm{m}}$.

$\mathrm{k}_{0} \quad$ : The load torque constant in N.m. Sec. ${ }^{2} / \mathrm{Rad}$.

$\mathrm{J}:$ : The inertia constant in $\mathrm{Kg}-\mathrm{m}^{2}$

B : The damping constant in N.m.Sec./Rad.

Assuming that, the motor angular velocity $\omega_{r}$ and the armature current $I_{a}$ are the desired state variables $x_{1}$ and $x_{2}$ respectively the equations (1) and (2) can be written in the matrix form as follows: 


$$
\left[\begin{array}{l}
\dot{\mathrm{X}}_{1}^{-} \\
\dot{\mathrm{X}}_{2}
\end{array}=\left[\begin{array}{cc}
-\frac{\mathrm{B}}{\mathrm{J}} & \frac{\mathrm{K}_{\mathrm{m}}}{\mathrm{J}} \\
-\frac{\mathrm{K}_{\mathrm{m}}}{\mathrm{L}_{\mathrm{a}}} & -\frac{\mathrm{R}_{\mathrm{a}}}{\mathrm{I}_{\mathrm{a}}}
\end{array}\right]\left[\begin{array}{l}
\mathrm{X}_{1} \\
\mathrm{X}_{2}
\end{array}\right]+\left[\begin{array}{cc}
0 & -\frac{1}{\mathrm{~J}} \\
\frac{1}{\mathrm{~L}_{\mathrm{a}}} & 0
\end{array}\right]\left[\begin{array}{l}
\mathrm{V}(\omega \mathrm{t}) \\
\mathrm{T}_{\text {Load }}
\end{array}\right]\right.
$$

The above equation is solved by using Matlab program and Runge-Kutta6 method [4].

Table 1 gives the parameters of the dc motor used in the simulation study [3].

\section{Table 1 Parameters of the dc motor}

\begin{tabular}{|c|c|c|c|}
\hline \multicolumn{3}{|c|}{$\begin{array}{l}\text { Rated armature voltage } \\
\text { Rated armature current } \\
\text { Rated rotor speed } \\
\text { Rated power }\end{array}$} & 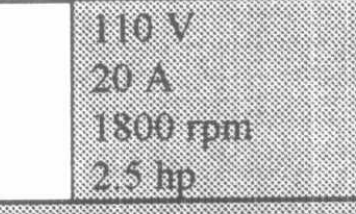 \\
\hline $\mathrm{R}_{\mathrm{a}}$ & 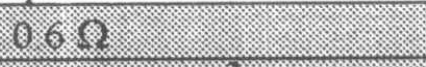 & $\mathrm{L}_{\mathrm{a}}$ & 8 \\
\hline $\mathrm{J}$ & 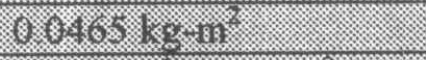 & $\mathrm{B}$ & (.). \\
\hline $\mathrm{K}_{0}$ & 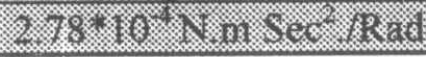 & $\mathrm{K}_{\mathrm{m}}=\mathrm{K}_{\mathrm{t}}$ & 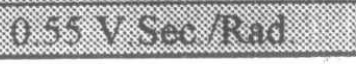 \\
\hline
\end{tabular}

\section{FUZZY LOGIC CONTROLLER}

Fuzzy logic control (FLC) theory was introduced by Zadeh [5], in 1965, but only recently its application has received large momentum. Fuzzy control systems are rulebased systems in which a set of so-called fuzzy rules represent a control decision mechanism to adjust the effect of certain system stimuli, such as, terminal voltage $V_{t}$, speed deviation $\Delta \omega$ and acceleration $\Delta \omega^{*}[6]$. The aim of fuzzy control systems is normally to replace a skilled human operator with a fuzzy rule-based system. The fuzzy logic controller provides an algorithm which can convert the linguistic control strategy based on expert knowledge into an automatic control strategy. Fig.(2) illustrates the basic configuration of a fuzzy logic controller which consists of a fuzzification interface, a knowledge base, a decision making logic, and a defuzzification interface [6].

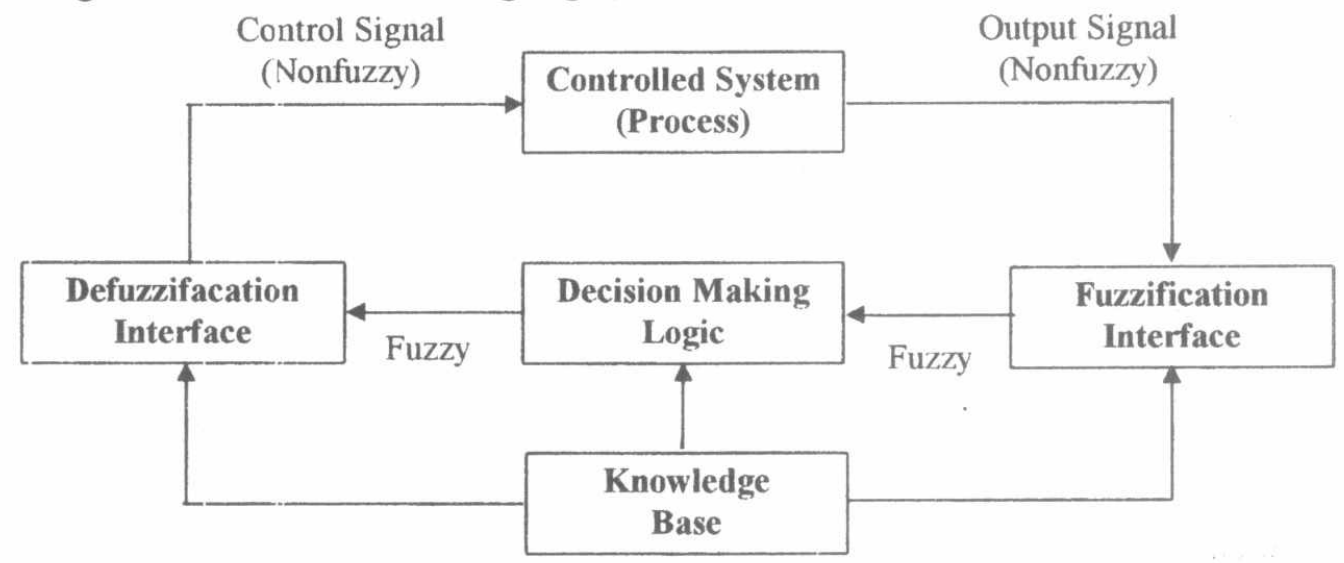

Fig.(2) The principle design of a fuzzy logic controller. 


\section{FUZZY LOGIC CONTROLLER FOR SPEED LOOPS}

The first step in designing a fuzzy controller is to decide which state variables representative of system dynamic performance must be taken as the input signals to the controller. Moreover, choosing the proper linguistic variables formulating the fuzzy control rules are also important factors in the performance of the fuzzy control system. Empirical knowledge and engineering intuition play an important role in choosing linguistic variables and their corresponding membership functions [6]. System variables, which are usually used as the fuzzy controller inputs include: states, states error, states error derivative, states error integral, etc. In dc motor drives, based on previous experience, the motor speed error $(\Delta \omega)$ and acceleration $\left(\Delta \omega^{\circ}\right)$ are chosen to be the input signals of the fuzzy controller. In practice, only shaft speed deviation is readily available. Hence, the acceleration signal can be derived from the speed signals measured at two successive sampling instants

$$
\Delta \dot{\omega}\left(K_{s}\right)=\frac{\Delta \omega\left(K_{s}\right)-\Delta \omega\left((K-1) T_{s}\right)}{T_{s}}
$$

where $T_{\mathrm{s}}$ is the sampling time. After choosing proper variables as input and output of fuzzy controller (according to control system structure), it is required to decide on the linguistic variables. These variables transform the numerical values of the input of the fuzzy controller, to fuzzy quantities. The number of these linguistic variables specifies the quality of the control which can be achieved using the fuzzy controller. As the number of linguistic variables increases, the computational time and required memory increase. Therefore, a compromise between the quality of control and computational time is needed to choose the number of linguistic variables. Basically, the sensitivity of a variable determines the number of fuzzy subsets. For the system under study, seven linguistic variables are used to describe each of the input and output variables. These are, LP (large positive), MP (medium positive), SP (small positive), VS (very small), SN (small negative), MN (medium negative) and LN (large negative)

In order to find the minimum and maximum values of stabilizer inputs, an open loop simulation for different initial conditions is performed. The results are used to find the minimum and maximum of the motor speed error $(\Delta \omega)$ and acceleration $\left(\Delta \omega^{\circ}\right)$.

After specifying the fuzzy sets, it is required to determine the membership functions for these sets. Functional definitions, which express the membership function of a fuzzy set in a functional form (typically a bell-shaped function, triangle-shaped function, trapezoidal-shaped function, etc.) is used to define the membership functions. The degree of membership can be defined as functions when the control variables amplitude are continuous[6]. In this paper, triangular membership functions are used to define the degree of membership for inputs and outputs. It is important to note that the degree of membership plays an important role in designing a fuzzy controller. A set of roles which define the relation between the input and output of fuzzy controller can be found using the available knowledge in the area of designing the dc motor control. These rules are defined 


\begin{abstract}
Proceedings of the $1^{\text {th }}$ ICEENG Conf. 24-26 March 1998
EP. 2 2 241

using the linguistic variables. The two inputs, speed and acceleration, result in 49 rules for each machine. A proper way to show these rules is given in Table 2 where all the symbols are defined in the basic fuzzy logic terminology. A typical rule has the following structure: Rule 1: If speed deviation is LP (large positive) AND speed derivative is LN (large negative) then the change in firing angle $\alpha$ is VS (very small).
\end{abstract}

Table 2 Decision table for controller output $\alpha$.

\begin{tabular}{|c|c|c|c|c|c|c|c|}
\hline $\bar{\lambda}$ & (1) & 1.11 & $8 \pi$ & 1.5 & SI & 13 & (1) : \\
\hline 113 & VS & SP & MP & LP & LP & LP & LP \\
\hline 111 & SN & VS & SP & MP & MP & LP & LP \\
\hline 40 & MN & $\begin{array}{l}\mathrm{SN} \\
\end{array}$ & VS & SP & SP & MP & LP \\
\hline 18 & MN & MN & SN & VS & SP & MP & MP \\
\hline 3N & $\mathrm{LN}$ & MN & SN & SN & VS & SP & MP \\
\hline 111 & LN & $\mathrm{LN}$ & MN & MN & SN & VS & SP \\
\hline 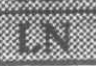 & LN & LN & LN & $\mathrm{LN}$ & $\mathrm{MN}$ & SN & VS \\
\hline
\end{tabular}

It is clear that each entry in Table 2 represents a particular rule. The above decision table can be transformed into the fuzzy relation matrix in the simulation study. The firing angle change is obtained by applying a particular rule expressed in the form of membership functions.

Now it is required to define the fuzzy region for the output for each fuzzy rule. There can be used different methods for finding the output, such as minimum-maximum or maximum-product. In this paper, the min-max method is used.

Fuzzy rules are connected using AND operators. The AND operator is used to obtain the minimum between input membership functions. Later, the minimum between this result and the output membership function is found. Finally, the output membership function of a rule is calculated. This procedure, is carried out for all the rules and for every rule a corresponding output membership function is obtained. To find the output membership function due to all rules, the maximum among all of these rules is calculated. Since a nonfuzzy signal is needed for the firing angle, by knowing the membership function of the fuzzy controller its numerical value should be determined. There are different techniques for defuzzification of fuzzy quantities such as Maximum Method, High Method, and Centroid Method. In this paper the centroid method is used.

In this defuzzification method, the weighed average of the membership function or the center of gravity of the area bounded by the membership function curve is computed in crder to be the most typical crisp value of the fuzzy quantity, i.e.: 
$\bar{y}=\frac{\int y \mu(y) d y}{\int \mu(y) d y}$

Fig.(3) illustrates the membership functions of input and output variables of the fuzzy controller. The basic structure for fuzzy speed control loop is shown in Fig.(4).

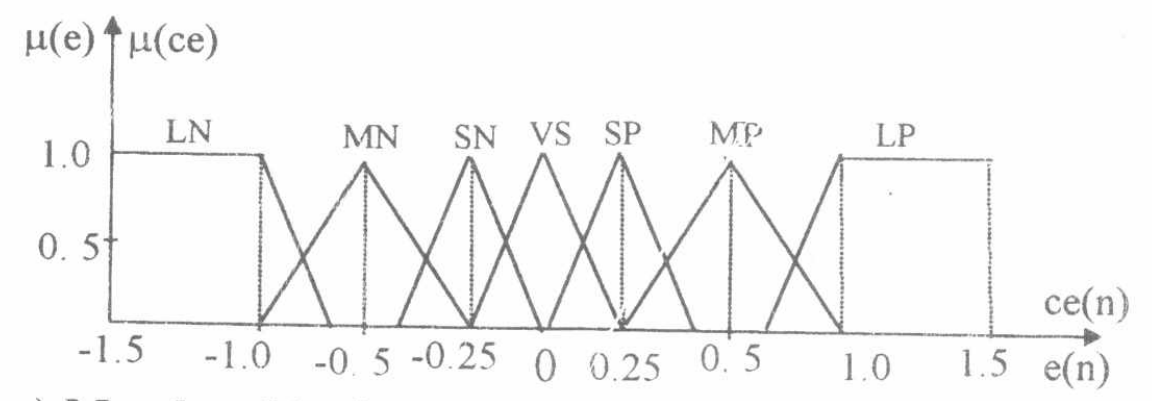

a) Membership function for input variable ce(n) and $e(n)$.

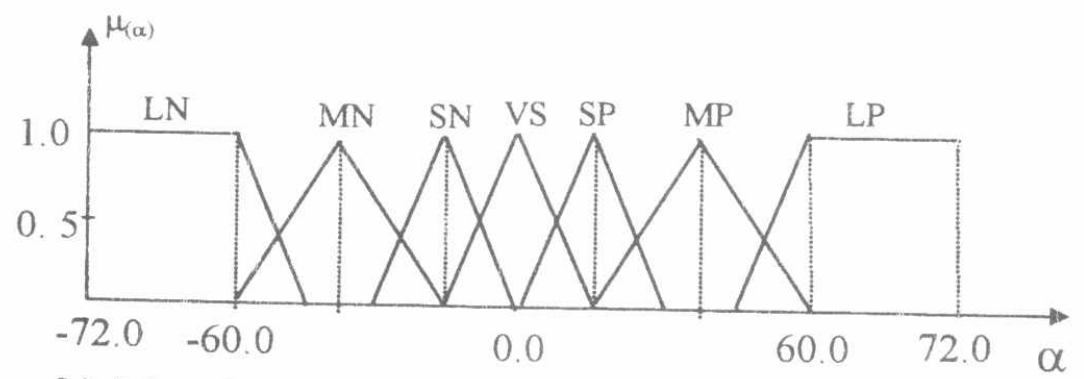

\section{b) Membership function for output variable}

Fig( 3) Membership functions, a) input variables (ce(n) and $e(n)), b)$ output variable $(\alpha)$.

Note that, the membership function for each linguistic variable is represented by triangular shape, and $50 \%$ overlap has been provided for the neighboring membership functions. It is evident that for any input data of $e(n)$ and $c e(n)$ there are four rules or less valid in the entire rule base table 2 .

The general input variables considered in the fuzzy rule base are:
$\Lambda \omega(k)=\omega r(k)-\dot{\omega} r(k)$
$\Lambda \omega^{\cdot}(k)=E(k)-E(k-1)$
For speed control loop
For change in error
(7) Where

for fuzzy speed controller, the error $\Delta \omega(k)$ at sampling interval $k$, is the difference between the feedback angular velocity $\omega_{\mathrm{r}}(\mathrm{k})$ and the reference angular velocity $\omega_{\mathrm{r}}^{*}(\mathrm{k})$. The input variables are normalized by devision by gain factor as follows: 


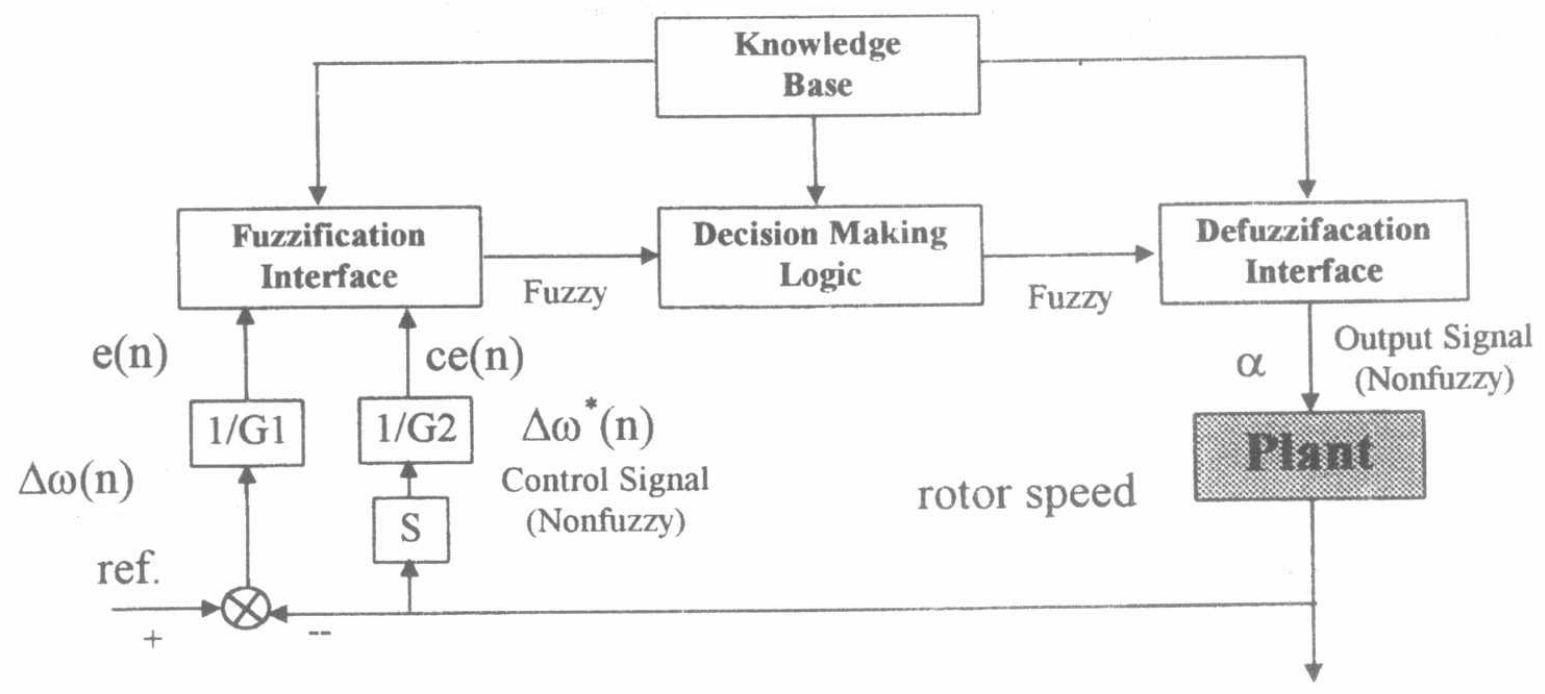

Fig.(4) Basic structure of fuzzy speed control loop for the controlled system

$$
\begin{aligned}
& \mathrm{e}(\mathrm{n})=\Delta \omega(\mathrm{n}) / \mathrm{G} 1 \\
& \mathrm{Ce}(\mathrm{n})=\Delta \omega^{\circ}(\mathrm{n}) / \mathrm{G} 2
\end{aligned}
$$

Where, G1 and G2 are the respective gain factors of the controller. The gain factors are different dependent on sampling times. These gain factors are chosen by trial and error.

\section{SIMULATION RESULTS}

In order to validate the effect of sampling time on fuzzy logic control of dc motor drives, digital simulation study was made using Matlab. The speed control of the drive was also designed and simulated with PI control, in order to compare the performance with the respective fuzzy control. The compensation and feedback control algorithms were iterated several times until the best simulation results were obtained. The motor was operated at full load torque for four seconds, then the load torque was increased to $130 \%$ of its full load value for a period of three seconds, and then the torque was returned to the full load value. The armature current response for both fuzzy and PI controllers are shown in Fig.(5). The simulation results for rotor speed are shown in Fig.(6) to Fig.(10). Fig.(6) shows that the transiant response using PI controller is approximately the same over a wide range of sampling times $(10 \mathrm{msec} \div 100 \mathrm{msec}$.). This response is obtained by adjusting the PI coefficients by trial and error (see table 3 ). The speed response using fuzzy controller at three different sampling times is shown in Fig.(7). We notice that the response is improved by decreasing the sampling time of the controller. Thus a fast computer is required to implement the fuzzy controller in order to obtain good response. Fig.(8) to fig.(10) show that the PI controller is better than the fuzzy controller at large sampling periods, while the fuzzy controller is superior at small sampling periods. 
Table 3 The coefficient for fuzzy and PI controller

\begin{tabular}{|c|c|c|c|c|}
\hline Controller & \multicolumn{2}{|c|}{ PI } & \multicolumn{2}{c|}{ Fuzzy } \\
\hline $\begin{array}{c}\text { Sampling time } \\
\text { (sec.) }\end{array}$ & KP & KI & G1 & G2 \\
\hline 0.01 & 0.059 & 0.001 & 300.5 & 350.9 \\
\hline 0.04 & 0.236 & 0.01 & 97.8 & 101.9 \\
\hline 0.10 & 0.595 & 0.01 & 8.3 .4 & 104.9 \\
\hline
\end{tabular}

\section{CONCLUSION}

This paper is intended to demonstrate the successful application of fuzzy logic control to phase-controlled converter dc motor drive system. The study clearly indicates that the response using conventional Pl controller is not affected by varying the sampling, time over a wide range. Where the transient response of the dc motor drives under fuzzy control is improved by decreasing the sampling time. So, a high speed processor is neede:d in this case.

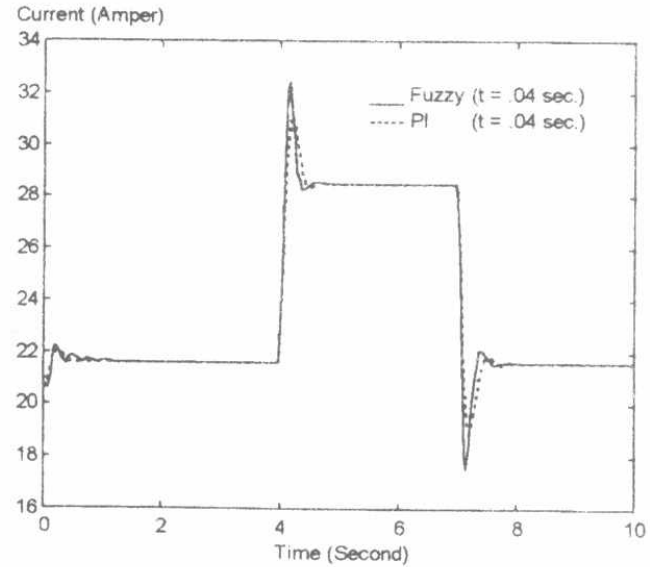

Fig.(5) The armature current response for both and PI controllers at $t=0.04$ sec.

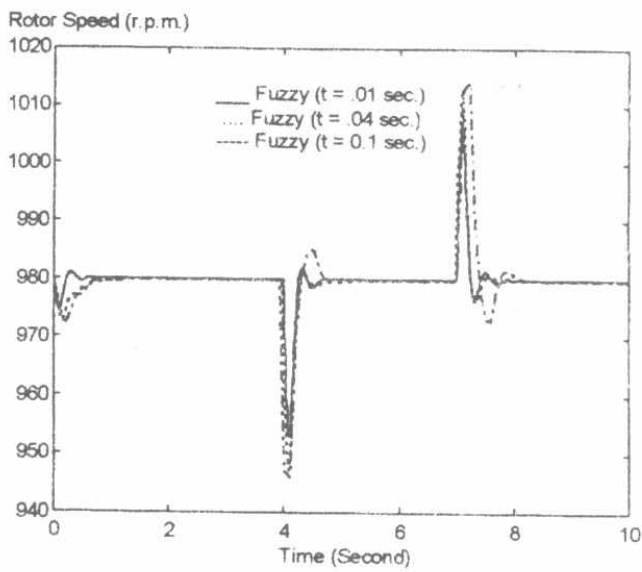

Fig.(7) Fuzzy controller at three different sampling times.

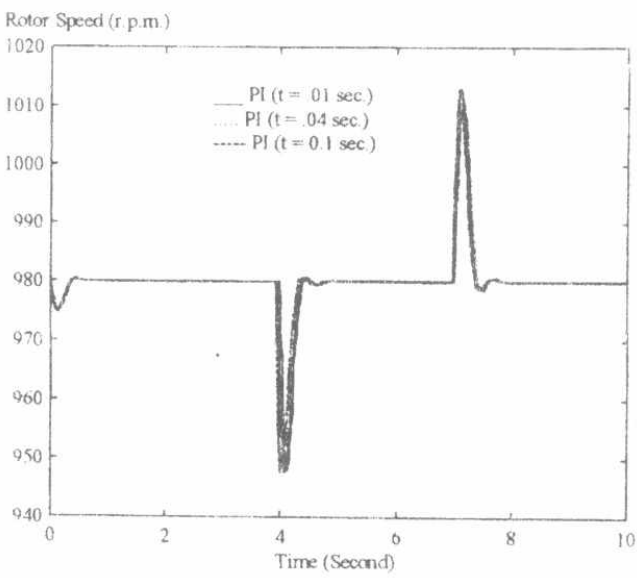

Fig.(6) PI controller at three fuzzy different sampling times.

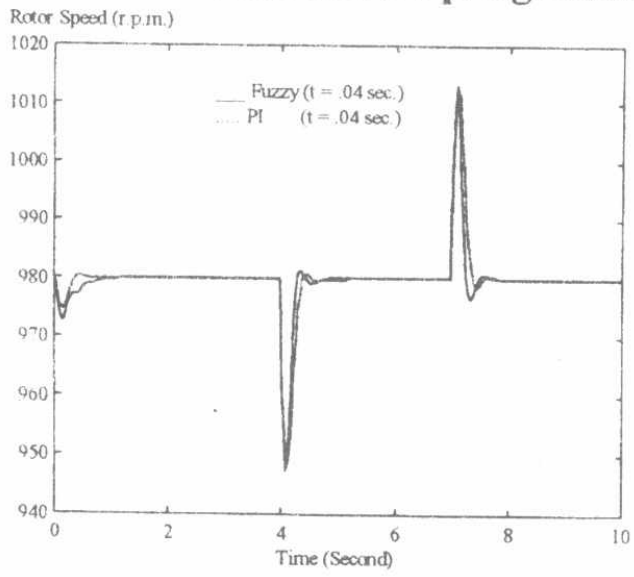

Fig.(8) Fuzzy and PI controllers at sampling time $=0.04 \mathrm{sec}$. 


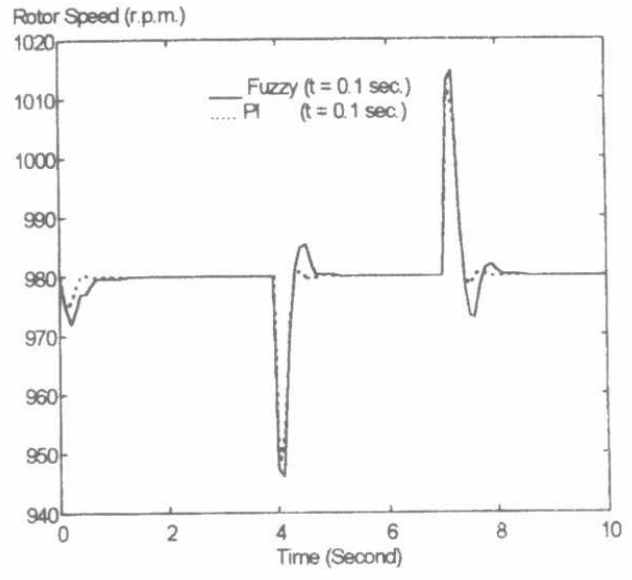

Fig.(9) Fuzzy and PI controllers at sampling time $=0.1$ sec.

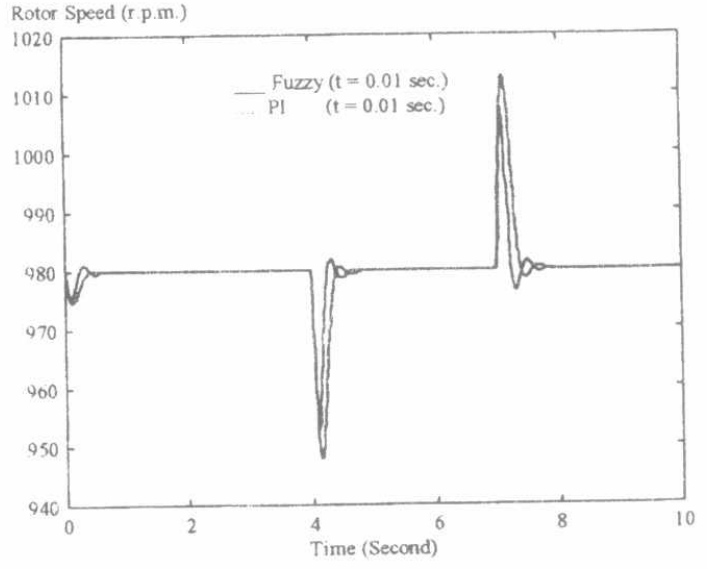

Fig.(10) Fuzzy and PI controllers at sampling time $=0.01 \mathrm{sec}$.

\section{REFERENCES}

1- A. Sabanoie and D.B. Izosimov, "Application of sliding mode to induction motor control,” IEEE Trans. Ind. Applicat., Vol. 17, No.1, PP.4149, 1981.

2- C. M. Liaw and S. Y. Cheng," Fuzzy two-degree-of-freedom speed controller for motor drives," IEEE Tran. on Indust. Elec., Vol. 42, No. 2, 1995.

3- A. M. Hussein, M. Hallouda and K. A. El-Metwally," Application of fuzzy logic in the speed control of dc motor," Al-Azhar Engineering fourth international conference, December, 1995.

4- W. Sabry," An algorithm for solving mulivariable multidifferential equation problems," Int. J. Math. Educ. Sci. Technol. , Vol.27, No. 1, 1996.

5- L. A. Zadeh, “Fuzzy set,", Information and control, Vol. 8, PP.338-353, 1965.

6- H. A. Toliyat, J.Sadeh and R. Ghazi, "Design of augmented fuzzy logic power system stabilizers to enhance power system stability," IEEE Tran. on Energy Conver., Vol.11, No.1, 1996. 
